become incorporated with the post-cretaceous continent, ${ }^{*}$ it is with much satisfaction that I find views for the most part so similar developed by Professor Huxley with the ability which marks all his work. Nevertheless, I venture to submit that the view I then advanced as to the period of the origin of the Eocene types is more in accordance with the 'acts, as far as we know them, than the hypothesis of their origin in a detached province during the Mesozoic period.

The view I advanced was that great changes in the distribution of the continents and seas took place at the close of the Palæozoic, and again at the close of the Mesozoic epoch; and so far I am at one with Professor Huxley : but I inferred that the geographical changes taking place at the close of the Mesozoic epoch were accompanied by the formation of a continent extending over all the geologically knoven parts of the globe, whose endurance was so prolonged as to have afforded the necessary time for the evolution upon it of the Eocene types.

In support of this inference I dwelt upon the entire disappearance of the orders Pterosauria, Enatiosautia, and Dinosauria among vertebrates, and of the Ammonitide among invertebrates; as well as upon the great extinction that took place in various other forms of life. Such a process as the one suggested by Mr. Huxley would lead us to look in Eocene strata for an intermingling of these distantly evolved types with forms belonging to the several orders just named; however much these forms might in their specific, or even in their generic characters, have been changed during the interval in which these distantly evolved types were introduced. But instead of this we find an absolute disappearance of several important orders of life, of which, from their habitat, some-especially the Pterosauria-would seem to have been independert of geographical changes simply.

Mr. Huxley intimates that he is led to his view by arguments which he had previously used to demonstrate the necessity of the existence of all the Eocene types in some period antecedent to the Eocene; but may we not suppose that the interval thus marked by the disappearance of so many great orders was vast enough even for this evolution? Indeed so much did this great extinction weigh upon me that even the intervention of a vast lapse of time seemed scarcely sufficient ; and I felt driven to suppose that these geographical changes in some degree altered the general conditions under which life had previously existed; and that this alteration, while stimulating evolution on the newlyformed continent, contributed to the great extinction which marks the intra-cretaceous and Tertiary epoch.

Subtle as are the causes which have brought into existence, the various types of being, those which have produced their extinction are not less so; though they have not yet received that attention which has been directed to the origin of species. I feel how crude were the suggestions I offered in I860 to explain this great extinction, and how wide a field of conjecture upon the subject is left open; for these orders of life were not only various in their habitat, but equally various in their food. We may imagine the extinction of a species to take place from failure of its food, from destruction by enemies, or-and I think this may be a cause more potent than any other, especially with forms possessing great fecundity-by a failure of the reproductive function; just as among men families diminish and eventually leave no descendants. Be the causes, however, what they may, this great extinction requires us, I submit, to suppose the occurrence - of an interval of time as great, and accompanied by changes of conditions as complete, as any that we can urge as necessary for the evolution of the Eocene types. Moreover, the cretaceous period itself, whose terrestrial fauna is as yet unknown, may, so far as we yet know to the contrary, have witnessed in the European area the commencement of, or even some progress in, the evolution of the Eocene types.

Brentwood, March ro

$$
\text { Searles V. Wood, Jun. }
$$

Transactions of the Royal Society of Edinburgh

Wirth reference to G.'s letter in the last number of NATURE, $I$ have merely to observe that (as you will see by the accompanying list) the Transactions of the Royal Society of Edinburgh are regularly sent to no less than twenty-three different societies, institutions, or museums in London alone-besides being sent

* "On the probable events which succeeded the close of the Cretaceous period;" read before the Geological Society on February Ist, 1860. The publication of the paper, beyond a brief abstract, having been denied by the Council, the desideratum was kindly supplied by Dr. Francis ; and the pape in exrenso is given in the Philosophical Magazine of March, April, and May, 882 ; the title having been changed to "The form and distribution of the Land 'Tracts during the Secondary and Tertiary periods, \&c." to many Honorary and Ordinary Fellows resiling there. As regards the special case of the British Museum, I have in my possession at this moment their acknowledgments of receipt of the successive parts of our Transactions up to March 1869 , and expect immediately to hear that they have received our last published Pait.

J. H. Balfour, Sec. R. S. Edirz.

\section{Euclid as a Text-Book}

"THE first four books of Euclid : or the principal properties of triangles, and of squares and other parallelograms treated geometrically : the principal properties of the circle and its inscribed and circumscribed figures treated geometrically." Such is the wording of the programme put forth by the University of London, of the Mathematical portion of the examination for matriculation candidates. Whether the papers have ever been drawn up in accordance with it I cannot say, but certainly my experience for the last four or five years has led me to believe that the alternative side has, of late, at least, been altogether ignored.

The slightest inspection of recent papers will show that they are constructed on the Euclidean type, and so long as Euclid was generally taught in schools, I think rightly so. But that such a course should now be persisted in (with such latitude as the programme provides) is hard upon those establishments which have taken up the modern views of the subject, such as those so ably advocated by Professor Hirst," and Mr. J. M. Wilson of Rugby.t. It can hardly be thought that so advanced an examining body as the London University will continue to act as an obstructive-for non-encouragement is almost tantamount to tabooing the subject; and the practical result of persistence, I fear, will be this, that the course pursued will press unfairly upon those schools in which (as in University College School, where Wright's Geometry is now the text-book) Euclid has been almost \pm discarded. Boys are required to study in their school work this modern geometry, founded on French mathematical works; and yet, seeing what value is set upon the same in the examination papers I am discussing, feel themselves constrained to read Euclid that their prospects of good places may be enhanced.

I am disposed to believe that "something will shortly be done," but the reform, though it ought rightly to commence here, ought not to stop here. Every examining body, if a fair field is to be given to the students of modern geometry, should put forth a scheme similar to that which heads my letter, and not merely put it forth "as a sop to Cerberus," but act upon it and let it be a reality.

University College School

R. TUCKer

MECHANICAL PROPERTIES OF ICE, AND

THEIR RELATION TO GLACIER MOTION

$A$ FEW weeks ago I prepared for the February num$A$ ber of the Alpine fournal a review of the contributions made by the Rev. Canon Moseley to the theory of glacier motion, which have appeared at various times during the last fifteen years in the Proceedings of the Royal Society and the Philosophical Magazine. Some new facts having come to my knowledge since the publication of my paper, I, venture to recur to the subject, and to invite discussion upon those memoirs of Canon Moseley in which he endeavours to prove that the descent of glaciers by their weight alone is a mechanical impossibility. $\S$ The arguments he advances in support of this conclusion may be epitomised as follows :-

If a transverse section of a glacier were to be made, the ice would be found to be moving differently at every point of it. The velocity is greater at the surface than deeper down, at the centre of the surface than the edges. There is a constant displacement of the particles of ice over one another, and alongside one another, to which is opposed the resistance known as shearing force. By the property of ice called regelation, where a surface so sheared is

* In his college lectures, and lectures to ladies at St. George's Hall, \&c. "Euclid as a text-book of Elementary Geometry" (read before the London Mathematical Society, and printed in the Educational Times, Sept. 868), and in his "Elementary Geometry."

$\ddagger$ A lmost. In consequence of pressure from without, arising from the cir\& Ptances with which my letter deals, Euclid is again read in one class.
Proceedings of the Royal Society, Jan. 7, I869. Philos. Mag., May 1869. Philos. Mag., Jan. 1870. 